To cite this article: Kok-Sing Tang, Mihye Won \& David Treagust (2019): Analytical framework for student-generated drawings, International Journal of Science Education, DOI: 10.1080/09500693.2019.1672906

\title{
Analytical Framework for Student-Generated Drawings
}

\author{
Kok-Sing Tang, Mihye Won and David Treagust \\ STEM Education Research Group, School of Education \\ Curtin University, Perth, Australia
}

\section{Corresponding Author:}

\author{
Kok-Sing Tang \\ kok-sing.tang@curtin.edu.au
}

\begin{abstract}
This article presents the development, description, application, and discussion of an analytical framework to examine students' drawings of scientific concepts and processes. Student-generated representation, particularly drawing, is increasingly emphasised as an important learning strategy to help students reason, explain, and demonstrate their scientific thinking and understanding. Although this strategy would require a greater need to understand what students are drawing, there are currently few frameworks that can support researchers and educators in analysing student-generated drawings. Based on the theory of social semiotics and an empirical data corpus of students' drawings from two research projects, we developed an analytical framework to describe and categorise a broad range of ideas and relationships that students are representing through their drawings in physics and chemistry. The application of this framework will be illustrated by two analytical examples of students' drawings in the topics of rotational moment and chemical bonding. The first example analysed students' drawings in relation to their accompanying written explanations, while the second example analysed the students' drawings in conjunction with the occurring classroom discourse. Through the illustration, the research and pedagogical applications and usefulness of this analytical framework will be discussed.
\end{abstract}

Keywords: Visual analysis, drawing, multiple representations, student-generated representations, learning with representations, multimodality, social semiotics

This is the peer reviewed version of the following article: Kok-Sing Tang, Mihye Won \& David Treagust (2019) Analytical framework for student-generated drawings, International Journal of Science Education, 41:16, 2296-2322, which has been published in final form at 10.1080/09500693.2019.1672906. This article may be used for non-commercial purposes in accordance with Wiley Terms and Conditions for Use of Self-Archived Versions. 
To cite this article: Kok-Sing Tang, Mihye Won \& David Treagust (2019): Analytical framework for student-generated drawings, International Journal of Science Education, DOI: 10.1080/09500693.2019.1672906

\section{Introduction}

Visual representations (e.g., drawings, schematics, animations, graphs) are indispensable to scientific thinking and learning. Learning how to interpret and draw conventional scientific diagrams (e.g., force, circuit, particle model, cell structure) has been an important part of the science curriculum. In recent years, there is a growing focus on the use of students' drawings as a learning and reasoning strategy to support pedagogies to guide students in generating, refining, and justifying representations in science (e.g., Quillin \& Thomas, 2015; Prain \& Tytler, 2012). At the same time, representations are increasingly used to support the learning of scientific practices such as modeling, explanation and argumentation (e.g., Oliveira, Justi, \& Mendonça, 2015; Namdar \& Shen, 2016). This recent focus on student-generated drawings reflects a growing theoretical understanding among science education researchers on the role of representations to support learning with representations, rather than learning from representations (Tang, Delgado, \& Moje, 2014).

Despite the focus on student-generated representations, there are currently few analytical frameworks that can be used to examine students' drawings. Researchers have thus far developed frameworks focusing on: (a) classification of representations (e.g., Ainsworth, 2006; Hegarty, Carpenter, \& Just, 1991), (b) analysis of print images in science textbooks (e.g., Ge, Unsworth, Wang, \& Chang, 2018; Meneses, Escobar, \& Véliz, 2018), (c) analysis of multiple and multimodal representations used in classrooms (e.g., Tang, 2016; Tang et al., 2014; Prain, Tytler, \& Peterson, 2009) and assessment of students' drawing and writing as a multimodal unit (e.g., Wilson \& Bradbury, 2016). However, none of these frameworks specifically addresses how to analyse students' drawings in science.

A framework to analyse students' drawings should ideally describe and categorise a broad range of ideas that students are representing. Not only can the framework provide a systematic and comprehensive way of examining students' drawings and the ideas that are represented by the drawings, it can also guide the analyst in interpreting students' reasoning and understanding that are contextual to the subject matter. Having such a framework will be the first step toward developing a tool that will support teachers to use students' drawings in the teaching and learning of scientific concepts and practices. With a focus on meaning making, the goal is to help teachers understand how students make scientific meanings through their drawings and consequently design appropriate instructional scaffolds with the use of visual representations to mediate their learning.

The purpose of this paper is thus to present and illustrate an analytical framework on students' self-generated drawings that were collected over several years in two research projects. The development of the framework, which consists of several levels and categories of analysis, will first be presented and explained. It will then be applied to analyse students' drawings in two specific topics - rotational moment in physics and chemical bonding in chemistry. The physics example illustrated how the students' drawings was analysed in relation to their accompanying written explanations and the chemistry example illustrated the visual analysis in conjunction with the occurring classroom discourse (with speech and gesture). Both analyses will be used to illustrate and discuss the research affordances and application of the analytical framework. 
To cite this article: Kok-Sing Tang, Mihye Won \& David Treagust (2019): Analytical framework for student-generated drawings, International Journal of Science Education, DOI: 10.1080/09500693.2019.1672906

\section{Theoretical Perspectives}

\section{Social Semiotics}

The theoretical basis of the framework presented in this paper is informed by social semiotics, which is a theory developed to understand how people use various semiotic systems such as language and images to make meanings in a discourse community (Halliday, 1978; Lemke, 1990). In particular, three key concepts from social semiotics form the theoretical underpinnings of this study, namely semiotic system, text and choice.

A semiotic system is an accumulation of culturally shaped signs that are developed and used by a community as resources for making meaning. According to Halliday (1978), every semiotic system has evolved and continues to evolve as a system of signs organised according to the interests and communicative needs of a particular discourse community. Thus, a visual system - consisting of images and diagrams, evolves as an accumulation of the way a particular community uses and shapes visual resources in order to make certain meanings demanded in that community (Kress \& van Leeuwen, 2006). As the communicative needs of various discourse communities are different, multiple visual systems have been developed that are specific to the needs of particular disciplinary areas, such as art and mass media (O'Toole, 1994), architecture (O'Toole, 2006), and of course science (Lemke, 1998).

While a semiotic system is an accumulation or network of all possible signs that are available as meaning-making resources for a community, a text is a particular instance of how the signs are produced to make meaning in a specific context. The relationship between a system and text is dialectical and mutually constitutive. For example, just as the semiotic system of language affords and constrains what we can write in any text, the production of texts over many instances can in turn affect the larger network of how written language is used, and consequently change the system over time. This is how the English language as a system has evolved and will continue to evolve. In social semiotics, the term 'text' is not limited to a stretch of written language, but is generalised to any inscription produced by its corresponding semiotic system.

Besides explaining the evolutionary development of semiotic systems and representations at a phylogenetic (community) level, social semiotics also accounts for how meanings are made through representations at an ontogenetic (individual) level. From a learning development point of view, the representations encountered by a user aggregate to become a repertoire of resources for him or her to draw upon in future to make meanings in new encounters. This is consistent with how Vygotsky (1986) had theorised the relationship between language and cognitive development, whereby the representations (e.g. words, images) learned on a social plane are internalised to become the basis of our thought process and development of scientific concepts (Tang, 2011). Through this relationship between representation and conceptual understanding, learning is therefore an iterative "process of sign-making" (Kress, Jewitt, Ogborn, \& Tsatsarelis, 2001) where students make use of available representations to generate new understanding, and at the same time, make new representations based on their new understanding. In this sense, representations serve as both an enabler and evidence of content learning. 
How a user selects semiotic resources to make meanings in their drawings in any particular instance is explained by the notion of choice, which is influenced by two different factors. The first factor is related to the semiotic system where the choice of any sign with the system will afford and limit the types of meaning that could and could not be made. For instance, in a study by Tang et al. (2014), they reported that the choice of drawing a piece of sandpaper from a side-view perspective as opposed to a top-view perspective (within a visual system) allows a group of seventh graders to represent depth and consequently use this analogy to explain bacterial residue on surfaces. On the other hand, students who chose a topview diagram could not sufficiently explain the same concept because they had no way of visualising and representing depth. The second factor is related to the interest of the user, or sign-maker, in terms of selecting features from a semiotic system that are salient or apt in expressing what he or she has in mind through words, images or other representations (Kress \& van Leeuwen, 2006). As such, every sign made by a user is meaningful and it reflects the choices made in relation to the (a) relative affordances of the semiotic systems, and simultaneously, (b) the interest and intention of the sign-maker. In sum, analysing these choices can reveal how a person thinks about and portrays an aspect of reality in a particular way using the semiotic resources that are available.

With these theoretical underpinnings, we consider diagrams as a semiotic system of culturally shaped signs developed as meaning-making resources (see Tang, 2013). By analysing students' diagrams as texts that derive from the system, we can infer the meanings and ideas they had based on the choices they made to produce those texts.

\section{Visual Analysis}

Social semiotics has been used not only to provide a theoretical account of meaningmaking, but also applied to develop analytical tools for analysing representations in multiple semiotic modes (e.g., Halliday, 1994; Kress \& van Leeuwen, 2006; O'Halloran, 2000; O'Toole, 1994). According to Lemke (1998), any representation, whether it is a written text of words or a drawing of lines and shapes, simultaneously makes three general types of meaning ${ }^{1}$ : (a) presentational meaning to present our ideas and experiences about the world; (b) orientational meaning to enact our interaction and relationship toward the world and other people; and (c) organisational meaning to connect and organise separate elements together into a larger and coherent representation.

In the analysis of images, Kress and van Leeuwen's (2006) 'grammar of visual design' is a pioneering work that provides a useful framework for researchers to analyse visual representations. However, Kress and van Leeuwen's (2006) framework was developed from their analysis of visual images in multiple disciplines (e.g., art, media studies, social studies, science \& technology) and media format (e.g., paintings, photographs, film, schematic diagrams, colour print, computer graphics, maps). Although there are some examples of images used in science, many categories in the framework are not directly

\footnotetext{
${ }^{1}$ In the context of language analysis, Halliday (1994) calls the 3 types of meanings ideational, interpersonal and textual meanings, while in image analysis, Kress \& van Leeuwen (2006) call them re-presentational, interactive and compositional. We chose Lemke's (1998) taxonomy as it is the most widely used within science education.
} 
applicable to science education nor sufficiently extensive to capture the nuances of studentgenerated drawings in science. Furthermore, as the framework was developed for linguists and semioticians, it is inaccessible for researchers and educators to understand and apply in science education. For this reason, it was necessary to develop a new framework that suits our purpose of analysing scientific diagrams drawn by students. We therefore recontextualised Kress and van Leeuwen's framework based on a data corpus of students' drawings in high school physics and chemistry. Notably, we refined several categories in their framework and developed new categories in order to make them more relevant to scientific diagrams and more accessible to science educators.

\section{Methods - Development of Analytical Framework}

\section{Context of Data Sources}

The data that were used to develop our framework were based on two research projects in Country A and Country B (blinded for peer review purpose) that focused on student drawings as part of a teaching intervention to improve student learning of science concepts. The interventions in both projects involved the use of a Predict-Observe-Explain strategy (White \& Gunstone, 1992) where the students predicted the outcome of a demonstration before they observed and explained the phenomenon. They were then asked to draw and write their predictions and explanations. As the students had not learned the scientific concepts and explanations for the topic under investigation, their drawings and written explanations reflected their prior understanding of the subject matter (See Tang, Ho, \& Putra, 2016; Treagust, Won, \& McLure, 2017). Four teachers and 106 grade nine students participated in the first project while two teachers and 119 students participated in the second project.

The participating students in these two projects produced many diagrams as part of the interventions. The diagrammatic data from those projects provided a corpus to create the analytical framework proposed in this paper. In addition to covering a wide range of topics (e.g., Newton's Laws, forces, moment, density, wave, sound, kinetic theory of matter, chemical bonding, qualitative analysis, redox, electrolysis) for secondary school science, the diagrams from those projects were generated by students across a range of ability groups under a variety of instructional tasks. As such, the diversity in the diagrams is suited for establishing a broad framework to analyse students' diagrams under various cultural and pedagogical circumstances. For this study, a total of 594 scanned diagrams were collected and organised in relation to the year level and science topic for further analysis.

\section{Analytical Procedures \& Development}

The development of the framework involved an iterative cycle between a top-down perspective informed by theory and a bottom-up grounded inquiry based on data. Informed by Lemke's (1998) theory (based on Halliday's work) that all semiotic systems make 3 types of meaning - presentational, orientational and organisational, we developed a set of categories for each type of meaning. There are altogether seven main categories in the framework, namely association, spatial, movement, perspective, modality, connective, and textual contextualisation. Association, spatial and movement focus on presentational 
meaning, perspective and modality focus on orientational meaning, while connective and textual contextualisation focus on organisational meaning. Most of these categories also have sub-categories that further specify the various aspects of a main category. See Table 1 for a list of the categories/sub-categories.

Table 1. Categories and Sub-categories in the Framework (See Table 2 to 8 for elaboration and examples)

\begin{tabular}{lll}
\hline Types of Meaning & Main Category & Sub-category \\
\hline Presentational & Association & --- \\
\cline { 2 - 3 } & Spatial & Position \\
& & Alignment \\
& & Spacing \\
& & Distribution \\
\cline { 2 - 3 } & Movement & Relative size \\
\hline Orientational & Perspective & Relative scale \\
& & --- \\
\cline { 2 - 3 } & & Dimension \\
& Modality & Angle \\
& & Abstraction \\
\hline Organisational & Connective & Formality \\
& & Simplicity \\
\cline { 2 - 3 } & Textual & Temporal Sequence \\
& contextualisation & Comparison \\
\hline
\end{tabular}

For each category/sub-category, there is a range of relationships that denote a distinguishable feature or method of how an image is drawn under a particular category/subcategory. As explained in the theoretical section, relationships are the "choices" made by the students in selecting their repertoire of visual resources to represent their ideas. It is important to note that categories/sub-categories are not mutually exclusive, i.e., a diagram can exhibit many categories/sub-categories at once. However within a category or sub-category, relationships are mutually exclusive, i.e., once a choice has been made with regard to selecting a particular visual resource, alternative choices will be precluded. See Tables 2 to 8 for the list of relationships and examples for each category.

In the process of reviewing and adapting the literature (e.g., Kress \& van Leeuwen, 2006), the first author generated a tentative list of analytical categories and sub-categories (as described above), which was then used to examine the students' diagrams in the data corpus. Against each category/sub-category, commonalities and differences among the students' diagrams were examined to distil any distinct patterns and characterisations. Through this process, the various relationships for each category/sub-category were generated. Thus, the set of these relationships emerged from an inductive and systematic analysis of the data corpus, rather than developed a priori based on the literature. In an iterative manner, the set of categories/sub-categories and relationships were then refined, expanded, collapsed, and 
consolidated to reflect the main features of student-generated diagrams in science. This process was repeated several times until a suitable framework that covered the data corpus emerged (Lincoln \& Guba, 1985).

From this emerging framework, the first and second authors then went through each category in relation to its description and usefulness in analysing students' diagrams. They applied the framework to specific topics covered in the data corpus to assess its applicability. In particular, the framework was used as a coding scheme to analyse students' diagrams in these topics and spreadsheets were created to compare the frequency for various relationships in every category/sub-category. This process helped us to determine the relevance and usefulness of the framework for different topics, as well as test the robustness of the framework as an analytical coding scheme. At the same time, both authors also separately checked on each other's codes in order to establish a common interpretation. Any ambiguities were discussed and resolved collectively, which occasionally also involved modifying the analytical categories and sub-categories when necessary.

\section{Results - Description of Analytical Framework}

\section{Association}

The first category in the framework examines how the visual "objects" depicted inside a drawing are associated to one another through lines, proximity or other means that visually join them together. A visual object can be identified from its completeness and isolation from other objects in a drawing. The most commonly depicted objects are circles, boxes and other geometrical shapes that form the basic building blocks comprising the drawing. Using a linguistics analogy based on Halliday's (1978) systemic functional linguistics (SFL), these shapes function as the "participants", as expressed by nouns in a sentence, that represent things in the natural world. By analysing how these shapes are joined together, we can infer the kind of relationships between the things or participants that the drawer has in mind visually. We identified 5 possible relationships that can be depicted in association: independent, connecting, adjoining, intersecting and inclusive. Inclusive relationship can be further divided into partial inclusion, where the larger object is partially filled up by the smaller objects, leaving a lot of blank spaces, and exhaustive inclusion where the larger object is completely filled by the smaller objects (See Table 2 for an explanation and example of each of these relationships).

The relationships under association are mutually exclusive, that is, if a relationship between two objects is adjoining (touching boundaries), it cannot simultaneously be independent, connecting, intersecting and inclusive. However, most drawings usually contain more than two objects, and in such cases, there can be multiple associative relationships in a diagram, one for each pair of visual objects. For example, in a drawing of water vapour molecules, there will be one set of relationships between hydrogen and oxygen atoms (adjoining or intersecting), one set of relationships between $\mathrm{H}_{2} \mathrm{O}$ molecules (independent or connecting), and one set for the $\mathrm{H}_{2} \mathrm{O}$ molecules and the enclosing space (inclusive). 
To cite this article: Kok-Sing Tang, Mihye Won \& David Treagust (2019): Analytical framework for student-generated drawings, International Journal of Science Education, DOI: 10.1080/09500693.2019.1672906

Table 2. The Category of Association

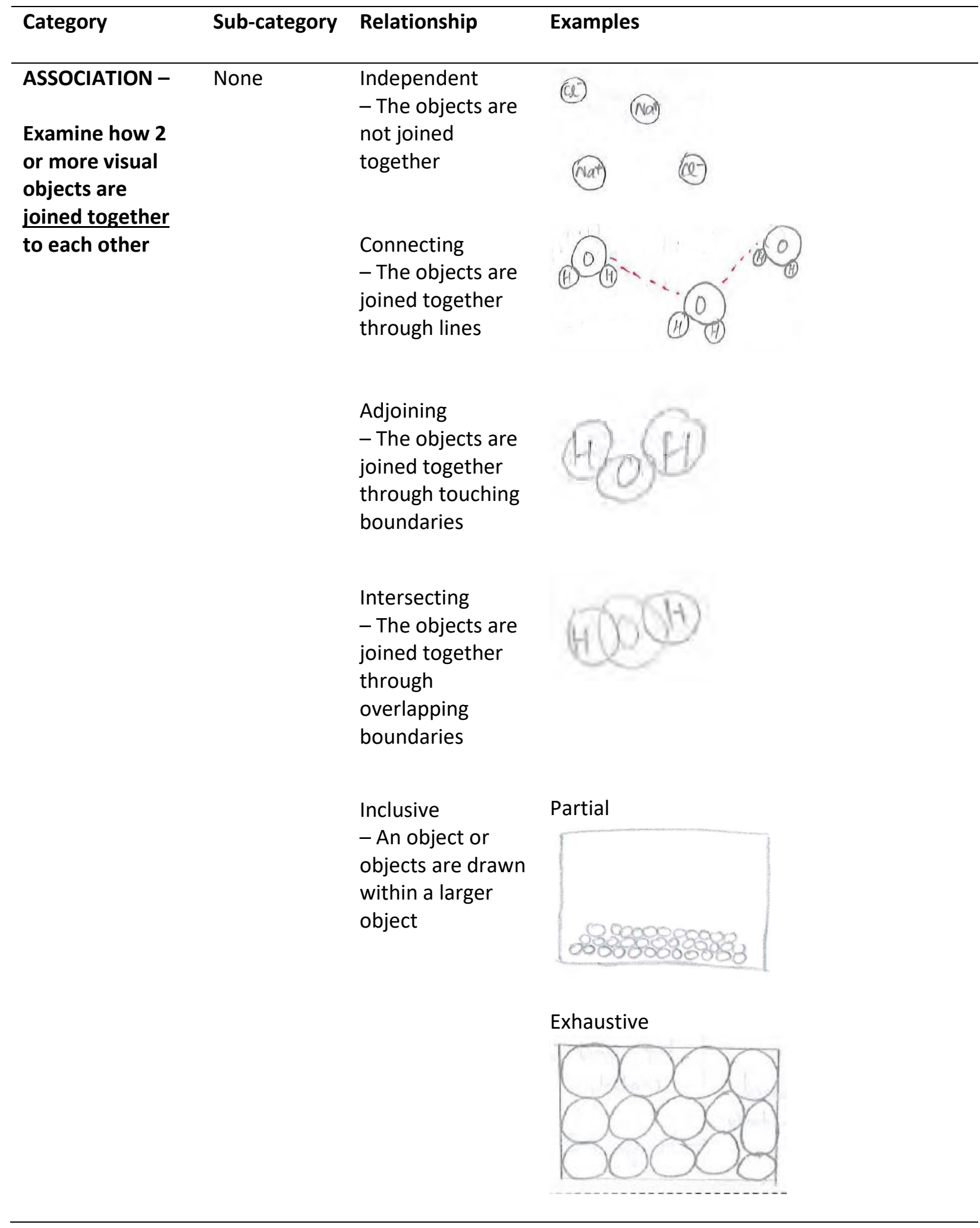


To cite this article: Kok-Sing Tang, Mihye Won \& David Treagust (2019): Analytical framework for student-generated drawings, International Journal of Science Education, DOI: 10.1080/09500693.2019.1672906

\section{Spatial}

This category in the framework examines how the visual objects depicted in the drawing are related to one another spatially through six sub-categories: position of the visual objects (top, bottom, left, right), alignment of the objects (parallel, angle, perpendicular), spacing (close or distant between objects), distribution (random or patterned arrangement among objects), relative size (object size in relation to one another) and relative scale (how spatially accurate the objects are in terms of their position, size and spacing). See Table 3 for further explanation and examples.

Table 3. The Category of Spatial

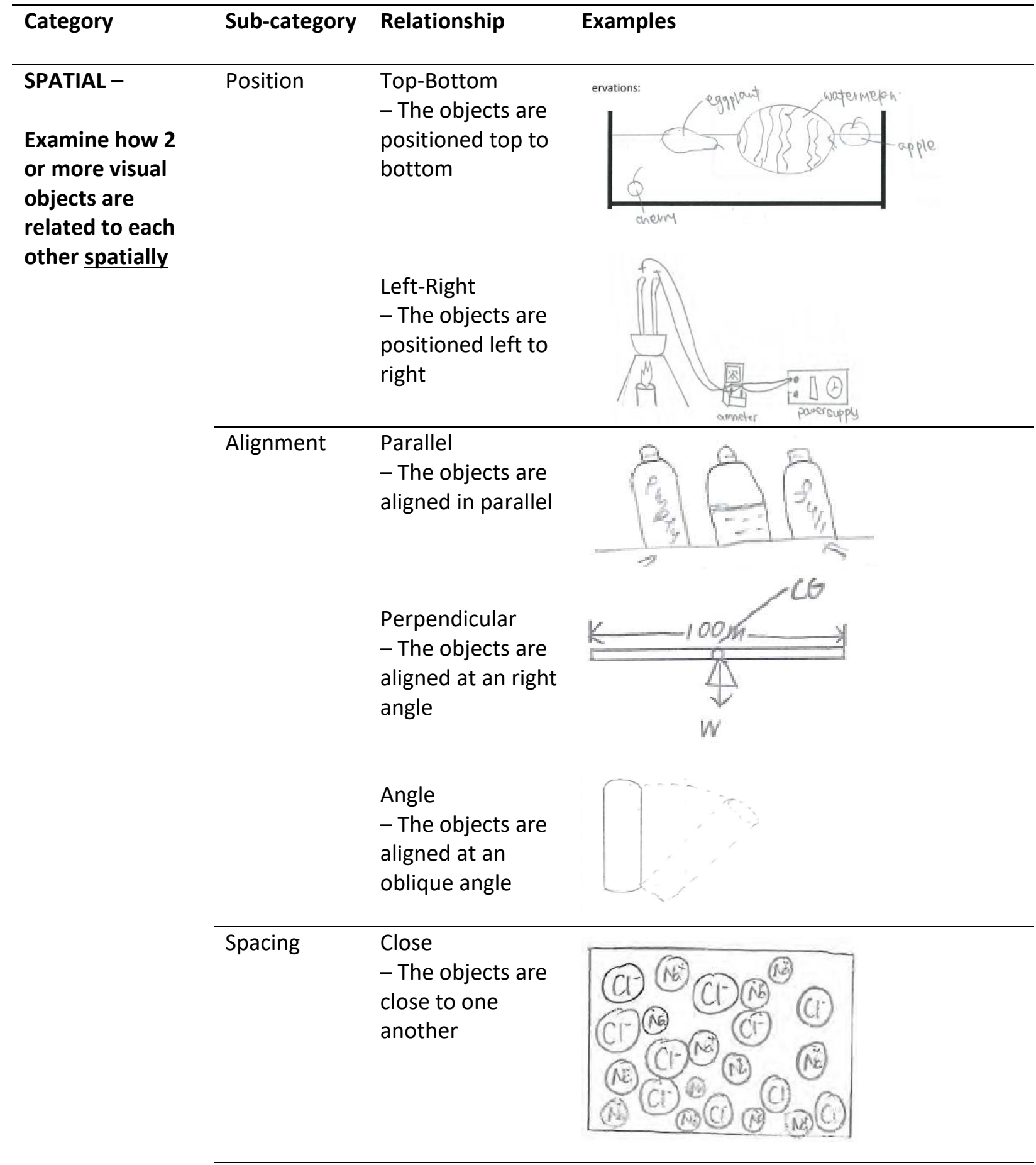


To cite this article: Kok-Sing Tang, Mihye Won \& David Treagust (2019): Analytical framework for student-generated drawings, International Journal of Science Education, DOI: 10.1080/09500693.2019.1672906

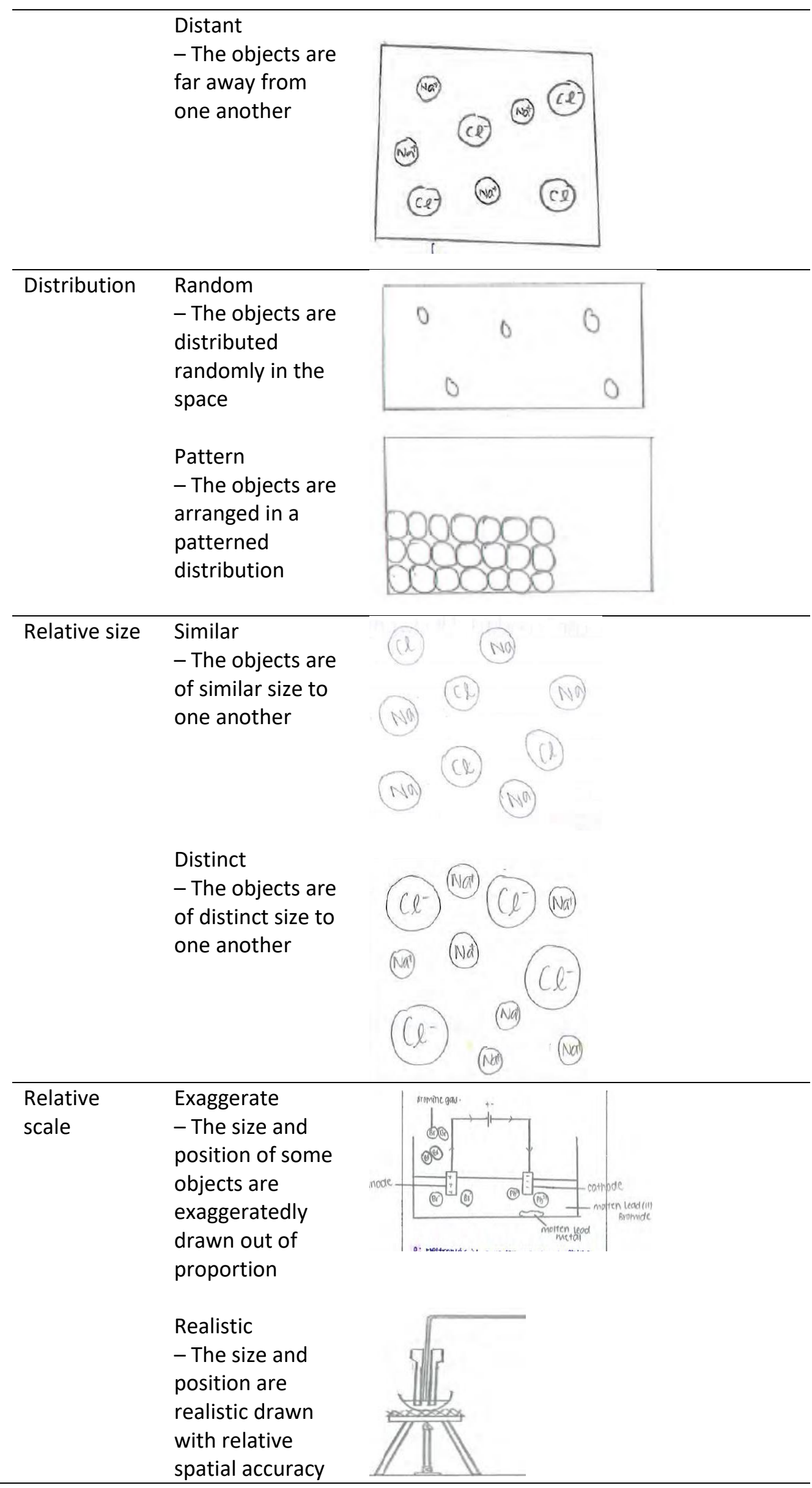




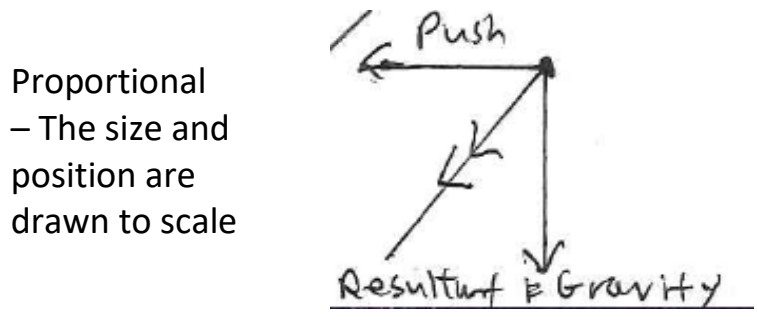

\section{Movement}

The third category examines how an object is drawn to depict any unfolding dynamic action or movement (See Table 4). Movement in drawings can be identified from the presence of a 'vector' formed by the depicted objects along a real or imaginary line (Kress \& van Leeuwan, 2006). This vector serves to present some kind of action, transition or unfolding event. From our analysis of students' drawings, we identified 3 usual methods in how movement are illustrated in the drawings: the use of arrow, path line and wavy lines.

Table 4. The Category of Movement

\begin{tabular}{lll}
\hline Category & Sub-category & Relationship \\
\hline MOVEMENT - & None & Arrow \\
& - using arrow to \\
indicate direction & of movement \\
Examine how a & & \\
visual object & & \\
moves or acts & Path line \\
dynamically & - using dotted \\
& line (or different \\
color) to trace a \\
previous position \\
or path taken \\
\\
Wavy lines \\
- using short \\
wavy lines around \\
an object \\
\end{tabular}




\section{Perspective}

The fourth category is perspective, which examines the point of view of how a visual object is depicted (See Table 5). There are three sub-categories under perspective: dimension (1, 2 or 3-dimensions), angle (top, side, oblique, mixed or projected view), and abstraction (macroscopic, microscopic, symbolic). The sub-categories of dimension and angle should not be confused as a spatial category. While spatial sub-categories examine the spatial relationships among the depicted objects (representing an objective description of the things in reality), dimension and angle examine the spatial relationships between the viewer and depicted objects (representing a subjective view of how a viewer sees or wants the audience to see the constructed reality from a particular point of view). This is why perspective is an orientational meaning rather than a presentational one.

Table 5. The Category of Perspective

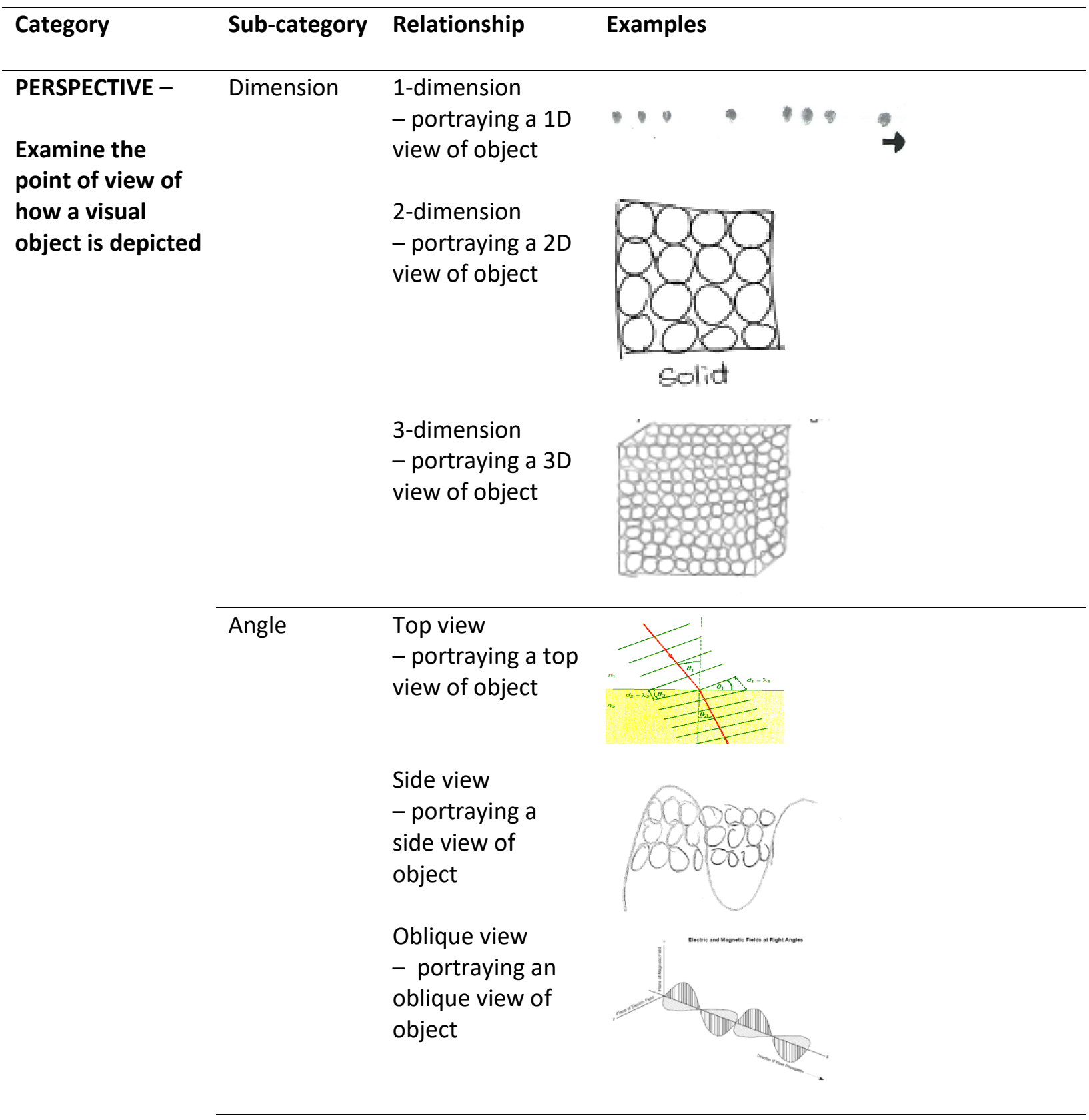




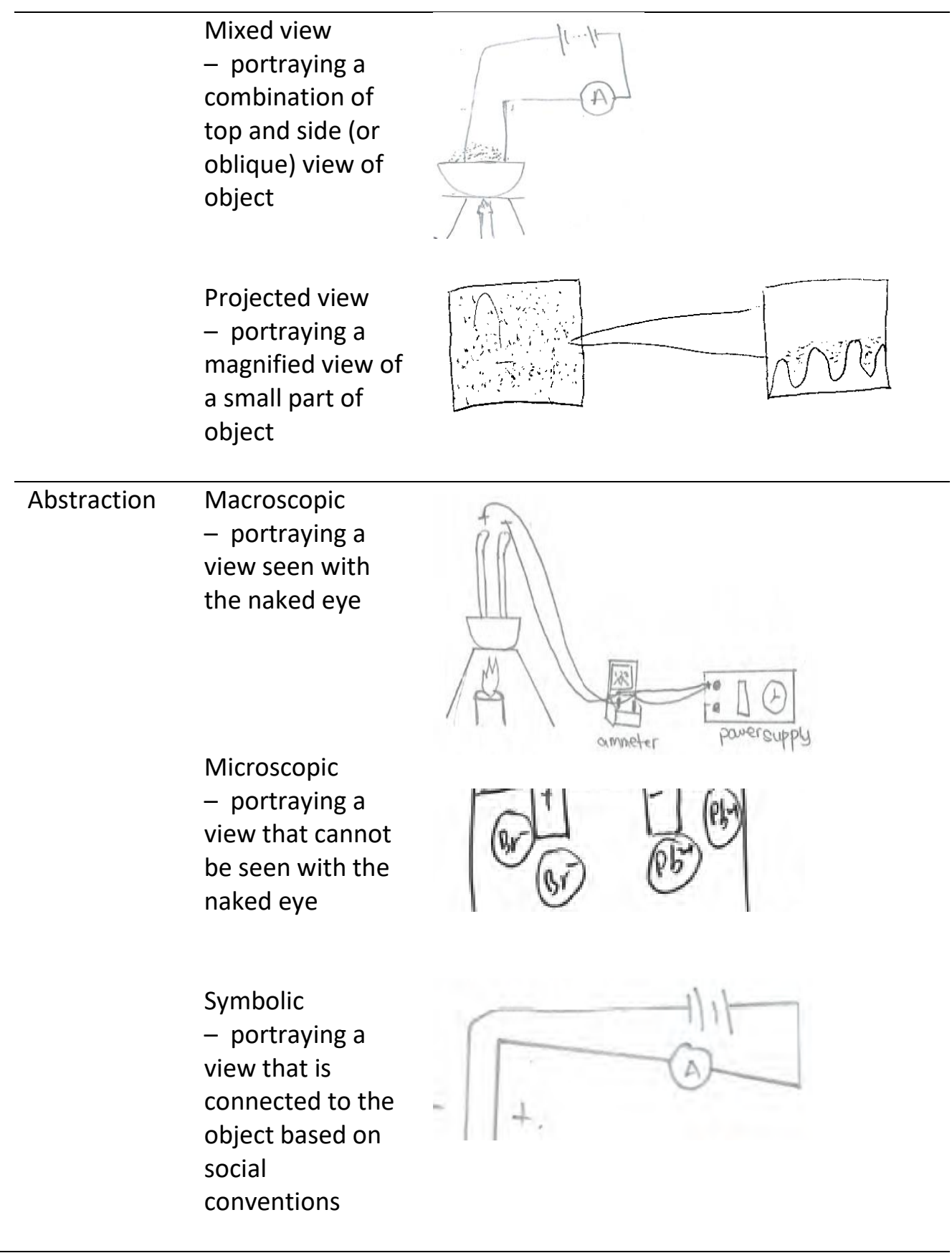

\section{Modality}

Another orientational meaning is modality, which reflects the credibility or truth value of a representation in terms of how close it resembles reality (See Table 6). As reality is constructed by the viewer and can be shaped by the way the representation is created by the author, modality is an orientational meaning instead of presentational. The modality of an image depends on the social discourse (Kress \& van Leeuwan, 2006). In mass communication for example, we ascribe more credibility (higher modality) to a photograph as compared to an artistic sketch showing the same object or event. Thus, modality in mass communication is related to naturalistic realism. However, in scientific discourse, modality is linked to universality and objectiveness rather than its realism. Thus, black-and-white 
schematic diagrams have a higher modality because they are applicable across localised settings. By contrast, photographs showing the same phenomena or experimental setup have a lower modality because they are seen as localised and limited to a particular laboratory. In the students' drawings, we identified two sub-categories of modality - formality, which examines the level of details and its perceived credibility and simplicity, which examines the style of drawing using shades and lines. Under these two sub-categories, schematic details with sharp lines are the highest form of modality.

Table 6. The Category of Modality

\begin{tabular}{lll}
\hline Category & Sub-category & Relationship \\
\hline MODALITY - & Formality & Cartoonish \\
- showing humor & exaggeration or \\
Examine the & caricature feature \\
truth value or & (low modality) \\
credibility of how & Iconic \\
a visual object is & - showing \\
depicted & observed objects \\
based on \\
resemblance \\
Schematic \\
- showing bare \\
essentials without \\
irrelevant visual \\
details (high \\
modality) \\
\\
Shades \\
- drawn with \\
shades or color to \\
give a sense of \\
realism (low \\
modality) \\
Sharp lines \\
- drawn with \\
clear and \\
continuous sharp \\
lines with no \\
color or \\
background (high \\
modality) \\
\\
Simplicity \\
\\
\\
\end{tabular}




\section{Connective}

Thus far, all the categories apply for drawings that show an object or cluster of objects at a particular instance. But what if a drawer needs to depict the passage of time or make some kind of comparison? This is where organisational meaning, focusing on how smaller textual/visual elements are organised to form a coherent representation, is relevant. One type of organisational meaning is connective, which examines how smaller visual elements are joined to make logical connections (See Table 7). These function similarly as connective words that are used to join clauses and sentences together. According to SFL (Halliday, 1994), there are four types of logical connections made by connective words, namely additive (e.g., and, in addition), temporal (e.g., next, then), comparative (e.g., however, while) and consequential (e.g., because, due to). In visual drawings, we identified only two types of visual connectives - temporal and comparative. Temporal sequences can be shown by numbering, arrow and ordered juxtaposition while comparison can be shown by unordered juxtaposition (side-by-side comparison). The use of arrow in temporal sequence can sometimes be easily confused with the indication of movement as explored in the earlier category, although it has a different function in denoting the passage of time rather than a spatial displacement of the object.

Table 7. The Category of Connective

\begin{tabular}{|c|c|c|c|}
\hline Category & Sub-category & Relationship & Examples \\
\hline \multirow[t]{2}{*}{$\begin{array}{l}\text { CONNECTIVE - } \\
\text { Examine how } \\
\text { smaller elements } \\
\text { within a complex } \\
\text { diagram are } \\
\text { joined together } \\
\text { to make logical } \\
\text { connection }\end{array}$} & $\begin{array}{l}\text { Temporal } \\
\text { Sequence }\end{array}$ & $\begin{array}{l}\text { Numbering } \\
\text { - using numbers } \\
\text { to indicate time } \\
\text { sequence of } \\
\text { images } \\
\text { Arrow } \\
\text { - using arrows to } \\
\text { indicate passage } \\
\text { of time } \\
\text { Ordered } \\
\text { juxtaposition } \\
\text { - using left to } \\
\text { right or top to } \\
\text { bottom sequence } \\
\text { to indicate before } \\
\text { and after }\end{array}$ & (1) (3) (2) air air as \\
\hline & Comparison & $\begin{array}{l}\text { Unordered } \\
\text { Juxtaposition } \\
\text { - comparing two } \\
\text { or more images } \\
\text { side by side }\end{array}$ & 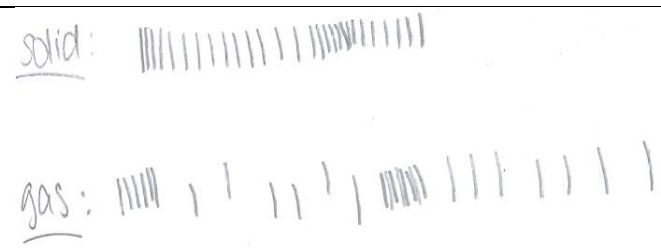 \\
\hline
\end{tabular}


To cite this article: Kok-Sing Tang, Mihye Won \& David Treagust (2019): Analytical framework for student-generated drawings, International Journal of Science Education, DOI: 10.1080/09500693.2019.1672906

\section{Textual contextualisation}

The last category accounts for how written texts, which often appear in students' drawings, are used to contextualise the meaning of a visual object. Written text can be used as a label (by inclusion, proximal or indexical) to indicate annotated diagrams, legend, or caption (See Table 8).

Table 8. The Category of Textual Contextualisation

\begin{tabular}{|c|c|c|c|}
\hline Category & Sub-category & Relationship & Examples \\
\hline $\begin{array}{l}\text { TEXTUAL } \\
\text { CONTEXTUALISA } \\
\text { TION - }\end{array}$ & Label & $\begin{array}{l}\text { Inclusion } \\
\text { - text inside an } \\
\text { object }\end{array}$ & (Nait) \\
\hline \multirow[t]{3}{*}{$\begin{array}{l}\text { Examine the use } \\
\text { of text to add or } \\
\text { contextualize } \\
\text { meanings to a } \\
\text { visual object }\end{array}$} & & $\begin{array}{l}\text { Proximal } \\
\text { - text next to an } \\
\text { object } \\
\text { Indexical } \\
\text { - text joined to } \\
\text { an object through } \\
\text { a line or arrow }\end{array}$ & $\frac{\text { paversuppy }}{\qquad D}$ \\
\hline & Legend & $\begin{array}{l}\text { - text separated } \\
\text { from the diagram } \\
\text { and connected } \\
\text { using same color, } \\
\text { shape or symbol }\end{array}$ & steam \\
\hline & Caption & $\begin{array}{l}\text { - longer text } \\
\text { (phrases or } \\
\text { sentences) for } \\
\text { entire diagram, } \\
\text { rather than } \\
\text { individual objects }\end{array}$ & $\begin{array}{l}\text { Weak intermolecular forces of attractiph } \\
\text { Vander waal's Fon }\end{array}$ \\
\hline
\end{tabular}


To cite this article: Kok-Sing Tang, Mihye Won \& David Treagust (2019): Analytical framework for student-generated drawings, International Journal of Science Education, DOI: 10.1080/09500693.2019.1672906

\section{Results - Application of Analytical Framework}

To highlight the applicability of the framework, we examined a corpus of students' drawings and illustrated two examples from physics and chemistry in this section. The first example examined the students' drawings in relation to their accompanying written explanations, while the second example examined the students' drawings in conjunction with the occurring classroom discourse.

\section{Illustration of Analysis in Physics (with Written Explanations)}

The first example is based on a physics lesson on rotational moment. The lesson was designed around a learning station approach where small groups of students rotate through 5 stations that explored different phenomena (called scenarios) related to the concept of moment. One of the scenarios focused on a roly poly toy that can return to its upright orientation when pushed over, due to the position of its centre of gravity. As the students explored this station, each of them wrote an observation and initial explanation with the aid of a diagram (see Figure 1). After the students had completed all the scenarios, the teacher discussed the explanations with the whole class. Based on the discussion, each student then drew a refined diagram and wrote a refined explanation. In the case of the roly poly scenario, the teacher drew a diagram on the board, which was copied by most students onto their worksheets. The teacher's diagram (as shown in green on the bottom of Figure 1) provided a reference diagram for us to compare with the students' diagrams.

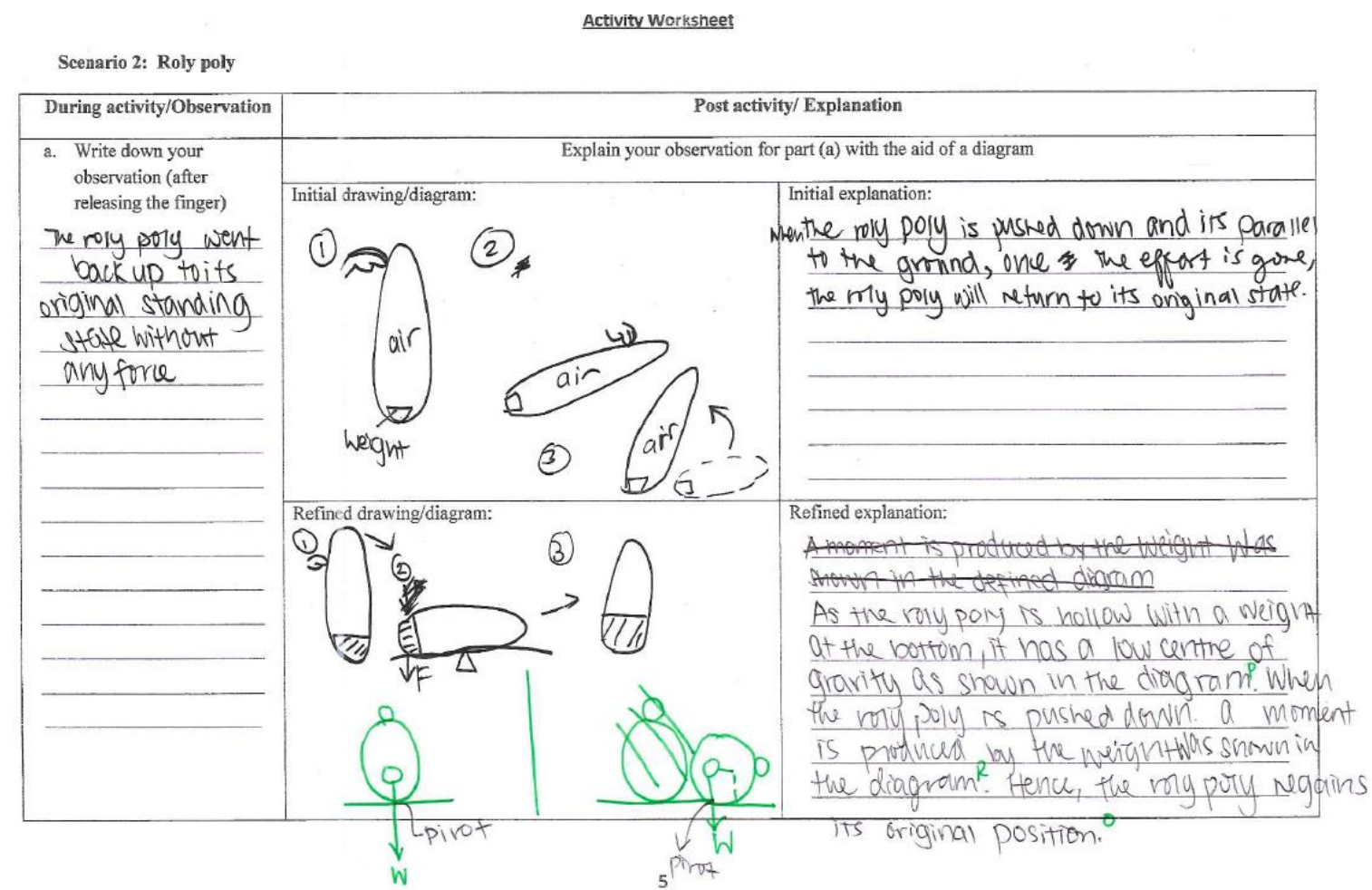

Figure 1. A sample of student's worksheet used in the physics lesson 
Analysis of the students' initial drawings using the framework revealed several important distinctions related to the categories of movement, connective, spatial and perspective, as compared to the reference diagram. In movement, the majority of students $(72 \%)$ depicted a sense of movement in the roly poly, with $24 \%$ using path line (e.g., Figure $2 \mathrm{a})$ and $60 \%$ using arrow (e.g., Figure 2c). In connective, about half of the students (48\%) drew multiple images of the roly poly to show a temporal sequence, with $20 \%$ using arrow (e.g., Figure 2b), 20\% using ordered juxaposition, and $8 \%$ of them using numbering (e.g., Figure 2c). The next category relevant to the analysis of the drawing is spatial, particularly on alignment. Most of the students (84\%) showed multiple positions of the roly poly in 2 different alignments, either horizontal and vertical (i.e., perpendicular) or horizontal and incline (i.e., angle), as shown in Figure $2 \mathrm{a}, \mathrm{b}$, and c. Lastly, in the category of perspective, the level of abstraction depicted by all the students is macroscopic. What this analysis indicates is that the majority of the students emphasised the following through their drawings: (a) the movement of the roly poly moving to and fro, (b) the temporal sequence caused by the application and removal of the force driving the action, (c) the alignment of the roly poly between its initial (upright) position and another (horizontal or incline) position, and (d) the macroscopic perspective of what they saw. Table 9 shows the distribution of the students' diagrams according to the movement, connective, spatial and perspective relationships.

(a)

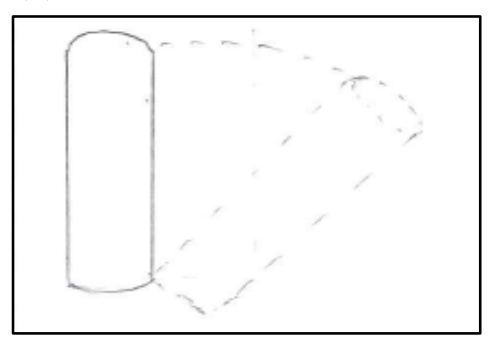

(b)

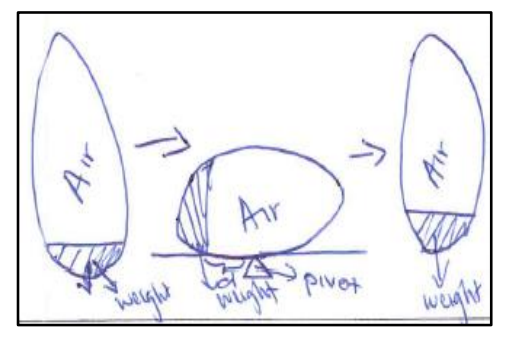

(c)

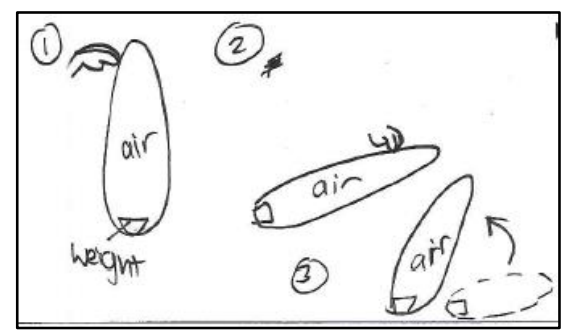

Figure 2. Students' diagrams to show movement, temporal sequence and alignment of roly poly:

(a) movement using path line, no temporal sequence, angled alignment

(b) no movement, temporal sequence using arrow, perpendicular alignment

(c) movement using path line and arrow, temporal sequence using numbering, angled and perpendicular alignment

The students' visual emphasis on movement, temporal sequence, alignment and macroscopic perspective is consistent with their initial written explanations. For example, consider the following students' explanation that accompanied the drawing shown in Figure 2c (also shown in Figure 1):

When the roly poly is pushed down and it's parallel to the ground, once the effort is gone, the roly poly will return to its original state.

In a similar way, the written statement emphasised the movement ("pushed down", "will return"), temporal sequence ("when", "and", "once", "will") and alignment ("parallel" and "original state"). Also, consistent with the macroscopic perspective, the subjects of the statement only involve concrete objects ("roly poly", "ground") without any abstract 
constructs (e.g., moment, centre of gravity). In this particular example shown in Figure 2c, the student also drew a hand (another macroscopic object) adjoining the roly poly, thus signifying the "pushing" and "effort" that is responsible for the movement and alignment of the roly poly. Although the drawing and written statement are consistent to each other, it is important to note that the overall explanation (written plus visual) does not sufficiently account for why the roly poly will return to its original position. This is where the students' drawings exhibit some gaps in relation to the reference diagram drawn by the teacher.

Table 9. Distribution of physics diagrams according to movement, connective, spatial and perspective relationships

\begin{tabular}{llc}
\hline Category & Relationship & $\begin{array}{c}\text { Number of } \\
\text { diagrams (n=25) }\end{array}$ \\
\hline Movement & Arrow, Path, \& Wavy & $18(72 \%)$ \\
& No Movement & $7(28 \%)$ \\
\hline Connective-Temporal & $\begin{array}{l}\text { Numbering, Arrow, \& } \\
\text { Ordered Juxtaposition }\end{array}$ & $12(48 \%)$ \\
& No Temporal Sequence & $13(52 \%)$ \\
\hline Spatial-Alignment & Perpendicular \& Angle & $21(84 \%)$ \\
& Parallel & $4(16 \%)$ \\
\hline Perspective-Abstraction & Macroscopic & $25(100 \%)$ \\
& Symbolic & 0 \\
\hline
\end{tabular}

Analysis of the reference diagram (reproduced in Figure 3) reveals several contrasting emphasis. First, there is no indication of any movement in the diagram. Second, there is also no explicit indication of a temporal sequence using numbering or arrow to show the passage of time from the upright to horizontal position. Although there is a juxtaposition of two positions (vertical and horizontal) in the diagram, the purpose of this juxtaposition is more for comparing the two positions rather than showing the dynamics of toppling the roly poly. These contrasts show that, in the context of explaining why the roly poly returns to its original position, it is not important to emphasise its movement or any time-bounded sequence. Instead, what accounts for the causal explanation is the shift in position of the roly poly's centre of gravity in relation to its pivot, and this shift is reflected in the reference diagram, under the analytical categories of abstraction and spatial.
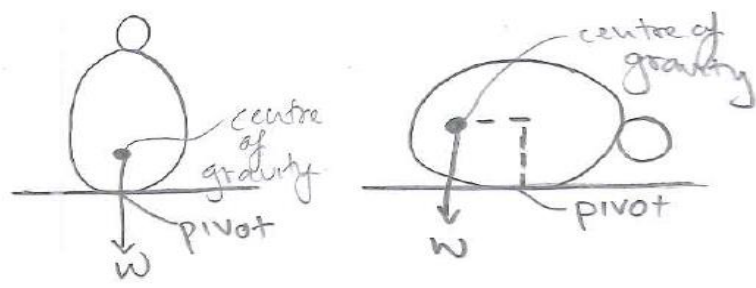

Figure 3. Diagram provided by the teacher 
In abstraction, there is an abstract level of representation showing the centre of gravity (an imaginery construct) and the force of gravity acting on it (W or weight), both of which are superimposed onto a macroscopic depiction of the outline of the roly poly. This is a major difference from the macroscopic perspective shown in all the students' drawings. Under spatial, similar to the students' drawings, there is an emphasis on a perpendicular alignment between the roly poly's vertical and horizontal positions. However, what is different and salient here is also the perpendicular alignment between two abstract lines - the line of action along $\mathrm{W}$ and the dotted line (called the moment or lever arm) from the centre of gravity to vertical line joining the pivot (see Figure 3). Showing this perpendicular alignment visually is important in order to account for the cause of the turning effect produced by $\mathrm{W}$ in returning the roly poly to its orginal position. All the students did not draw this aspect, and correspondingly, they also did not mention about the turning effect in their written explanation. Interestingly, the teacher did not highlight the gaps in the students' drawings during and after this lesson.

\section{Illustration of Analysis in Chemistry (with Classroom Discourse)}

As a contrast to the physics example, we provide another example taken from a lesson activity on chemical bonding. In the activity, the students were asked to state and explain whether de-ionised water can conduct electricity. The Predict-Observe-Explain (POE) strategy and a worksheet were used for students to write their predictions and initial explanations, with the aid of diagrams that show the molecular structure of de-ionised water in both solid and liquid state (see Figure 4).

\subsection{Properties of Covalent Substances (Simple Molecular and Giant Molecular)}

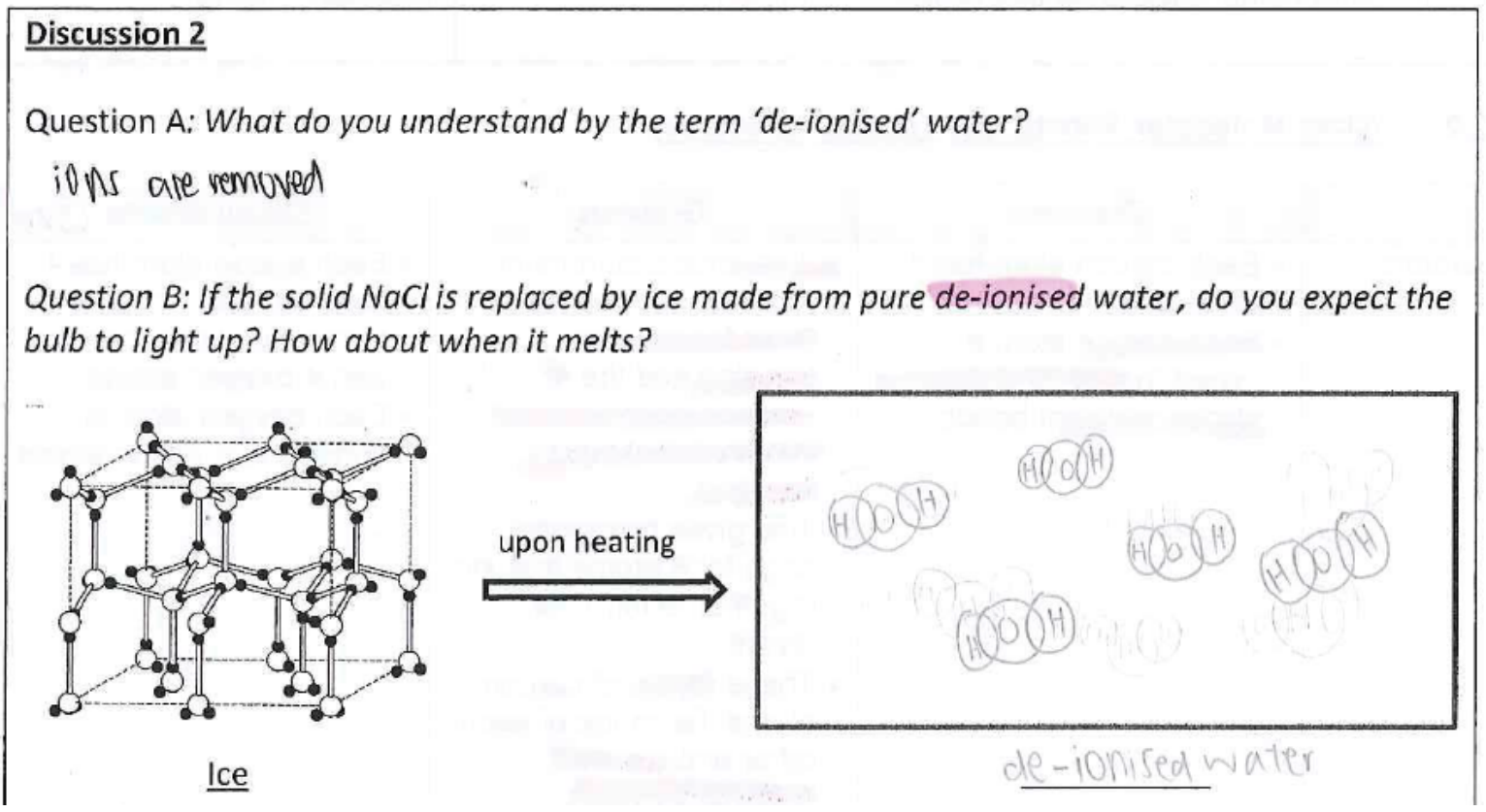

Figure 4. A sample of student's worksheet used in the chemistry lesson 
For this analysis, the categories most relevant to the drawing analysis are association and spatial. Specifically, we focused on two levels of association of water molecules in the diagram - between hydrogen and oxygen atoms (intra-molecular) and between water molecules (inter-molecular).

For intra-molecular association, we looked at how oxygen $(\mathrm{O})$ atom was linked to two hydrogen $(\mathrm{H})$ atoms. The range of drawings showed three different relationships independent, intersecting, and adjoining, with each signifying a different intra-molecular bond. A small minority of students (8\%) included completely separated hydrogen and oxygen atoms, floating independently (Figure 5a). The majority of students (92\%) drew intact water molecules with two hydrogen atoms linked to one oxygen atom as either intersecting (24\%) or adjoining (68\%). While the difference between these two relationships is subtle, each shows different meaning of $\mathrm{H}-\mathrm{O}$ bonding in water. The diagram with intersecting atoms (Figure 5b) implies the atoms are sharing some space to form a strong bond between $\mathrm{H}$ and O. The diagram with adjoining atoms (Figure 5c) suggests hydrogens are glued on the surface of oxygen rather than sharing a space.

(a)

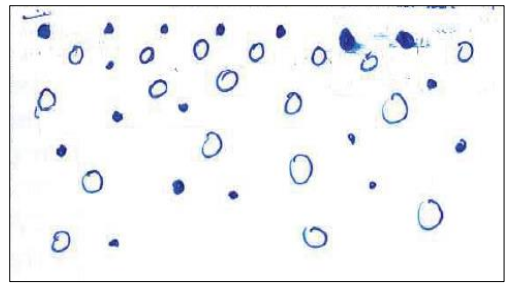

(b)

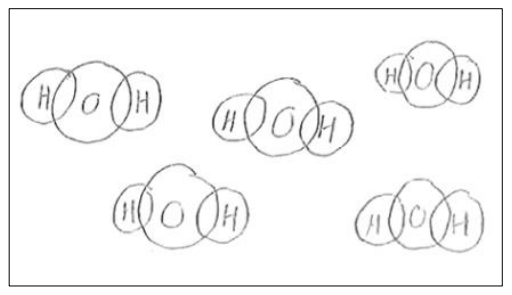

(c)

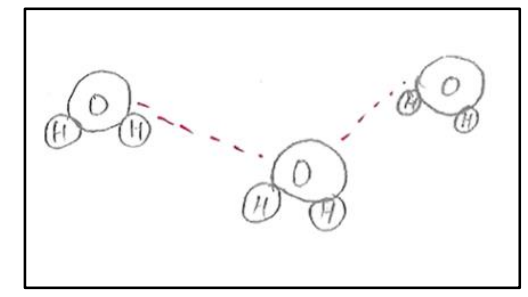

Figure 5. Students' diagrams to show different associations of water molecules:

(a) hydrogen atoms independent of oxygen atoms (no water molecules);

(b) independent water molecules with two hydrogen atoms intersecting one oxygen atom

(c) connecting water molecules with two hydrogen atoms adjoining one oxygen atom.

For inter-molecular association, the drawings showed two different relationships independent and connecting. About half of students (48\%) did not draw any intermolecular associations. Water molecules were floating around independently. On the other hand, 44\% of the students drew dotted lines to connect water molecules as seen in Figure 5c. (Based on video observation, many of the dotted lines were actually added after the teacher drew her diagram; see later excerpt). Table 10 shows the distribution of the students' diagrams according to the association relationship that were analysed.

Table 10. Distribution of chemistry diagrams according to association

\begin{tabular}{llc}
\hline Category & Relationship & $\begin{array}{c}\text { Number of } \\
\text { diagrams (n=25) }\end{array}$ \\
\hline Association: & Independent & $2(8 \%)$ \\
Intra-molecular & Intersecting & $6(24 \%)$ \\
(H-O bonding) & Adjoining & $17(68 \%)$ \\
\cline { 2 - 2 } & &
\end{tabular}


To cite this article: Kok-Sing Tang, Mihye Won \& David Treagust (2019): Analytical framework for student-generated drawings, International Journal of Science Education, DOI: 10.1080/09500693.2019.1672906

$\begin{array}{llc}\text { Association: } & \text { Independent } & 12(48 \%) \\ \text { Inter-molecular } & \text { Connecting } & 11(44 \%) \\ \text { (water-water connection) } & \text { No Molecular Depiction } & 2(8 \%)\end{array}$

The above analysis was used to support the interpretation of the occurring classroom discourse. After the students had completed the POE activity, the teacher asked two students to present their drawings to the class (through a document reader). The first student's drawing was similar to Figure 5b while the second student's drawing was similar to Figure 5a. The teacher then used both of their drawings to talk about the different kinds of bonding they needed to understand, as seen from the following excerpt:

\begin{tabular}{|c|c|c|}
\hline Line & Speaker & Utterance \& Gesture \\
\hline 1 & $\mathrm{~T}$ & $\begin{array}{l}\text { Now, why am I showing you this example? Because I want you to } \\
\text { understand that when I melt something, alright, a simple covalent } \\
\text { compound are actually. do not break the bond between them }\end{array}$ \\
\hline 2 & $\mathrm{~T}$ & $\begin{array}{l}\text { Alright, so what is it that I am breaking? ( } 9 \text { second wait time). Huh, if } \\
\text { you look at the diagram, what is it that I am breaking? }\end{array}$ \\
\hline 3 & $\mathrm{~T}$ & $\begin{array}{l}\text { Let me show you, you have this (drew an enclosing box followed by } 1 \\
\mathrm{H}_{2} \mathrm{O} \text { inside). Correct or not? So in the solid state, it was all packed } \\
\text { packed packed up (gestured with } 2 \text { hands to signify molecules inside the } \\
\text { enclosing space) }\end{array}$ \\
\hline 4 & $\mathrm{~T}$ & $\begin{array}{l}\text { Then in the liquid state, you showed me this (drew } 2 \text { more } \mathrm{H}_{2} \mathrm{Os} \text { a } \\
\text { distance away). At first, they supposed to be close and packed (gestured } \\
\text { with } 2 \text { hands over molecules to signify together). Closely packed. Then } \\
\text { after heating (drew an arrow to the left of the enclosing box), this is what } \\
\text { you get. What did you notice about the distance between the } \\
\text { molecules? (gestured with } 2 \text { hands over molecules to signify separated) }\end{array}$ \\
\hline 5 & S & Further \\
\hline 6 & $\mathrm{~T}$ & $\begin{array}{l}\text { They are further apart (drew a dotted line between two } \mathrm{H}_{2} \mathrm{Os} ; \mathrm{See} \\
\text { Figure } 6 \text { ). }\end{array}$ \\
\hline 7 & $\mathrm{~T}$ & $\begin{array}{l}\text { So. What kind of bonds are you breaking? (drew a line to the dotted } \\
\text { line). Is it a bond? To be very specific, what is it you are overcoming } \\
\text { here? }\end{array}$ \\
\hline 8 & S & (softly) Forces of attraction \\
\hline 9 & $\mathrm{~T}$ & The forces of? \\
\hline 10 & S & Attraction \\
\hline 11 & $\mathrm{~T}$ & Attraction. Good (Wrote forces of attraction linking to the dotted line) \\
\hline
\end{tabular}




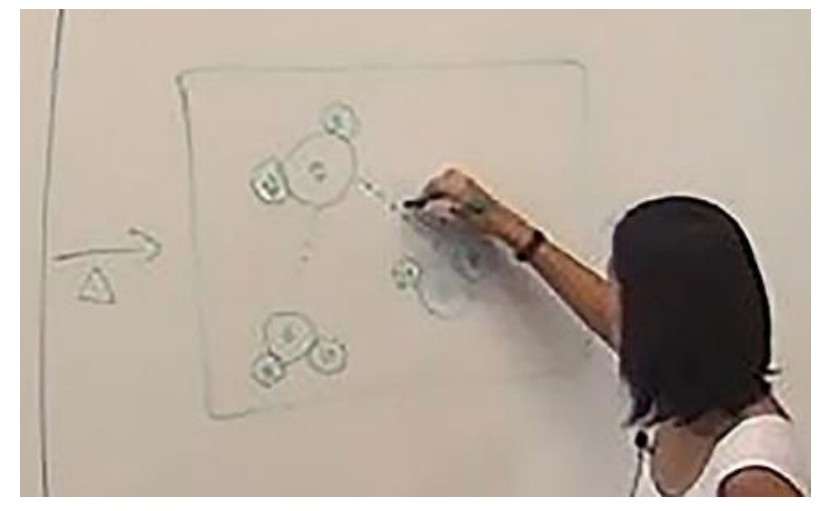

Figure 6. Diagram drawn by the teacher on the whiteboard

In this example, the teacher $(\mathrm{T})$ was implicitly showing three different types of association through her drawing: (a) an adjoining intra-molecular bond between $\mathrm{H}$ and $\mathrm{O}$ (line 1), (b) an independent inter-molecular relation between $\mathrm{H}_{2} \mathrm{Os}$ (line 2), and (c) a connecting inter-molecular attraction between $\mathrm{H}_{2} \mathrm{Os}$ (line 6-11). At the same time, her drawing, utterance and gesture from line 4 to 6 also highlighted the spacing in terms of how close or far apart were the $\mathrm{H}_{2} \mathrm{Os}$, but this is a spatial category. Consequently, there was some confusion in line 6 whether the dotted line drew by the teacher signified (a) the distance between two $\mathrm{H}_{2} \mathrm{Os}$ (corresponding to her simultaneous utterance "They are further apart" and previous utterance in line 4) or (b) the force of attraction (corresponding to her simultaneous writing of "forces of attraction" linking to the dotted line and subsequent utterances from line 7 to 11). This confusion was evident from the immediate excerpt, where a pair of students clarified with the teacher on their drawing to represent the force of attraction:

\section{Line Speaker Utterance}

10 T What's this? Which one are you drawing for me?

11 S I'm trying to (showed her drawing to T)

$12 \mathrm{~T}$ Ah, okay. Be very careful because in bold line being used right, they are termed as bonds. So when I draw it, you seem to imply that oxygen to oxygen there is one more bond here. So if you want to show in

\section{diagram form}

13 S Dotted line

14 T Yes, exactly

This excerpt shows the students were initially not clear about how to represent the inter-molecular association between $\mathrm{H}_{2} \mathrm{Os}$. When they used bold line, the teacher corrected them as the line could be interpreted as a bond instead of a force of attraction (line 12). Subsequently, the students understood they needed to use dotted line instead (line 13). In this case, the teacher only explained the difference between bold and dotted line to denote the nature of association between $\mathrm{H}_{2} \mathrm{Os}$ for these two students. However, she did not make it clear herself in the earlier excerpt on how to explicitly draw the different associations and the difference in using dotted line to represent either distance or force. As such, other students may not see the subtlety in terms of various associative meanings as well as spatial meaning as represented by drawing a line. 
To cite this article: Kok-Sing Tang, Mihye Won \& David Treagust (2019): Analytical framework for student-generated drawings, International Journal of Science Education, DOI: 10.1080/09500693.2019.1672906

\section{Discussion}

For the purpose of this paper, the application and usefulness of the analytical framework will be discussed in response to two key questions: (1) What value does the framework add to the analysis? (2) How applicable is the framework across topics, subject areas and research contexts?

\section{Affordance of Analytical Framework}

For the first question, we use the examples from moment and chemical bonding to discuss how the analytical framework had supported our analysis and interpretation of the students' drawings. First, the framework provided a comprehensive and hierarchical list of meanings that can be made through a diagram (a total of 48 possible relationships in 7 categories). This allowed us to systematically scan through the range of possible meanings and identify categories that were relevant to the topic being analysed. From the scan, we narrowed the relevant meanings to the identified categories of movement, connective, perspective-abstraction, and spatial-alignment for moment and association and spatialspacing for chemical bonding.

Each identified category then served to focus our attention to notice subtle features found in the students' diagrams and examine them in terms of the list of relationships provided in the framework. For instance, in the category of association, we were able to (a) distil the various ways students indicated the connections within and among water molecules in a liquid state as independent, connecting, adjoining, intersecting, or inclusive and (b) subsequently focus our interpretation to notice the confusion caused by the dotted line in representing various associative meanings as well as spatial meaning. In this aspect, the framework provided an "interpretive lens" (Cheney, 2000) to notice and make visible phenomena that tend to be subtle or hidden on the surface.

Besides functioning as an interpretive lens, the framework also provided a way for us to codify and categorise the ideas represented in the students' diagrams, and consequently making the observed phenomena possible for pattern recognition and communication between researchers. Because the framework is also a typology of the possible meanings that can be made through a diagram, it can be used as a coding scheme to systematically render the data into distinguishable categories of meaning. The purpose of this coding process is not to generate quantitative analysis and claims, but to facilitate an evidence-based interpretation to discern interesting or recurring patterns among the instances in the data.

Furthermore, the framework also provided a metalanguage for researchers to describe the observed patterns in terms of the meaning-making functions of the diagrams. The New London Group (1996, p. 77) defines metalanguage as a "language for talking about language, images, texts, and meaning-making interactions". As drawing is a form of language, it is useful to have a metalanguage (language about language) that will allow researchers to talk about and communicate the functions of images in our analysis.

Overall, the framework allowed us to describe and make claims about the students' diagrams based on systematic evidence, and thereby identify key features that are important 
to understand a particular conceptual situation. For instance, the students' diagrams might appear on the surface to be relevant to the topic being discussed (e.g., molecular arrangement to show chemical bonding, toppling roly poly to illustrate turning effect). However, a deeper analysis aided by the framework has revealed the diagrams were not emphasising the subtle meanings and relationships that are key to representing and explaining the phenomena. In the physics example, the spatial position of its centre of gravity (an abstract entity) was a key feature that was missing in the students' diagrams as they only emphasised the movement and temporal sequence of the roly poly. In the chemistry case, the ambiguity of the dotted line as simultaneously representing distance, bond and force of attraction caused an issue for some students. Thus, the framework was useful in identifying and describing how diagrams are used (or not used) to support key conceptual ideas in science. This identification can also apply to diagrams in textbooks as well.

\section{Applicability of Analytical Framework}

In the development of an analytical framework for visual representations, one of the issues often raised is how general and specific is the framework applicable for a range of topics and content areas. A framework that is topic-generic has wider appeal and applicability across more situations as compared to a topic-specific framework, but could be less useful for a more detailed analysis.

The framework that we developed is specific to scientific discourse but generically applicable to most topics and sub-disciplines within the natural sciences. Empirically, we have tested the applicability of the framework based on the data corpus that was available to us, which included a range of topics in physics and chemistry such as dynamics, kinetic model of matter, wave, sound, chemical bonding, redox reaction, and electrolysis. Due to this generalisability, the framework has the potential to provide a unifying analytic scheme to examine the meaning of any drawing (e.g., a line, circle) across various topics. For instance, the five sub-categories of association - independent, connecting, adjoining, intersecting, or inclusive - are applicable whether we are examining the relationships between microscopic objects such as electrons, atoms, molecules or cells, as well as macroscopic objects such as the connections between apparatus, equipment, strings, wires or connecting glass tubes.

In this study, although we do not have examples from biological and earth sciences (due to lack of data in those subject areas), there is no reason to imagine how drawings from those disciplines will be drastically different to the point where the framework is not applicable. Nevertheless, the lack of biology and earth science examples is still a limitation in this study and future research is needed to test and expand the categories and sub-categories in this framework to include a range of topics those areas.

While the relationships and categories in this framework can be applied generically to any topic in science, the interpretation of the specific meaning and significance of a diagram is always context dependent, both the social context in terms of the norms and conventions in the environment (e.g., classroom, subject area) and the local context as determined by what occurred prior to and at the moment the drawing was made. For example, an unbroken or dotted line joining two visual objects would denote some kind of relationship (classified as 
connecting association) in any context. However, whether the line signifies distance, an intermolecular force, or an imaginary reference line will depend on a number of contextual information, which the analyst must draw from the available data to inform his/her interpretation. Such contextual information usually involve domain-specific knowledge of the subject matter, curriculum goals, learners' prior knowledge, and the interaction that is occurring. Thus, other data sources besides the students' diagrams, such as written texts, videos or interviews, are often needed to support this interpretation process.

Consequently, it is important to point out that, consistent with the notion of multimodal meaning-making (Lemke, 1998; Tang, 2011), students' drawings (a visual mode) must not be interpreted in isolation from other modes of representation, particularly speech or writing. This is where data from other modes, such as written words, speech and gestures, should be used to support and contextualise the visual analysis. In the examples provided in this paper, we have demonstrated how data from two other sources (e.g., written explanations, classroom discourse) were used to support our interpretation. Both examples also highlighted how various categories and sub-categories from the visual analytical framework were applied in the multimodal analysis with verbal language and gesture.

\section{Implications}

The framework developed in this study can potentially benefit science teachers in using representations to support the teaching and learning of science. Research focusing on learning with representations has increasingly emphasised the importance of using studentgenerated representations to help students reason, explain, and demonstrate their scientific thinking and understanding (Ainsworth et al., 2011). To implement these pedagogical approaches, teachers need to have a clear framework to recognise representational features and meanings made in students' drawings. In this aspect, this analytical framework could serve as a starting point for further development into pedagogical guidelines and interventions.

One possible idea is to develop the framework into a teachers' guide in order to support teachers in getting students to generate and express their ideas through drawings. In science class, student-generated diagrams tend to be descriptive rather than explanatory. To encourage students to draw diagrams as part of their reasoning and problem solving, teachers need to identify key conceptual and representational features, instruct students what to include and how to include them in diagrams, and provide constructive and critical feedback on students' diagrams to improve their understanding. As such, the framework can be used as an interpretive lens for teachers to evaluate the ideas made by the students through their drawings and discern the subtle gaps that students tend to miss in their diagrams, particularly relationships related to association, spatial, movement, and temporal/comparative connective that are crucial to representing scientific phenomena.

The use of this framework as a metalanguage is not exclusive for researchers to facilitate their communication, but it is also applicable for teachers and students to explicitly describe their drawings and discuss the underlying ideas represented in their drawings during class. For instance, students can use the metalanguage of association (as connecting, 
adjoining, inclusive etc.) to communicate explicitly how their visual objects are connected to one another and explain what those connections represent. Doing so will help teachers and students pay attention to the multifaceted meanings of their drawing more methodically. Current research is looking into the development of a metalanguage that will assist teachers and students to describe the characteristic of drawings and other images as embedded within scientific experiments, explanations and arguments (Tang, 2019).

Another possibility is to extend the framework into an assessment rubric for teachers and students to evaluate the diagrams in relation to key ideas of specific topics. This can be used both as a formative assessment for students to reflect and continually improve their drawings with the aid of a metalanguage that was discussed earlier, as well as a summative assessment to evaluate the range of relationships that were represented through their drawings. In chemical bonding for example, we learned from the analysis that association and spatial relationships are crucial to represent visually the characteristics and behaviours of atoms and molecules. Therefore, through the rubric, teachers can direct students' attention to those key components: (a) the relationships between atom-atom, atom-molecule, and molecule-molecule and (b) their spatial dimension, spacing, alignment and distribution in a liquid state, and consequently how to represent these ideas visually. It is important to point out that the purpose of the rubric is not to have students learn and reproduce a narrow and standardised way of drawing these relationships. Some students could create alternatives way of representing the same relationships, as long as the reasoning for the representation is explained and justified. Instead, the purpose of the rubric is to direct the students' attention toward how to harness drawing as an important resource (besides verbal language) to facilitate their scientific reasoning.

Much research is still needed to turn these two prospects into pedagogical reality, and to advance this research further, what is needed currently is an analytical framework such as the one presented in this paper.

\section{Acknowledgement}

This work was supported by Department of Foreign Affairs and Trade, Australian Government [grant number AKF00588]; Education Research Funding Programme, National Institute of Education, Singapore [grant number OER 48/12 TKS].

\section{References}

Ainsworth, S. (2006). DeFT: A conceptual framework for considering learning with multiple representations. Learning and Instruction, 16(3), 183-198.

Ainsworth, S., Prain, V., \& Tytler, R. (2011). Drawing to Learn in Science. Science, 333(6046), 1096-1097. doi:10.1126/science.1204153

Bruner, J. S. (1990). Acts of meaning. Cambridge, Mass.: Harvard University Press.

Cheney, G. E. (2000). Interpreting interpretive research: Toward perspectivism without relativism. In S. R. Corman \& M. S. Poole (Eds.), Finding Common Ground (pp. 1745). Stirling, Scotland: Guilford. 
To cite this article: Kok-Sing Tang, Mihye Won \& David Treagust (2019): Analytical framework for student-generated drawings, International Journal of Science Education, DOI: 10.1080/09500693.2019.1672906

Crowder, E. M. (1996). Gestures at Work in Sense-Making Science Talk. Journal of the Learning Sciences, 5(3), 173 - 208.

Ge, Y.-P., Unsworth, L., Wang, K.-H., \& Chang, H.-P. (2018). Image design for enhancing science learning: helping students build taxonomic meanings with salient tree structure images. In K. S. Tang \& K. Danielssson (Eds.), Global Developments in Literacy Research for Science Education (pp. 237-258). Cham, Switzerland: Springer.

Halliday, M. A. K. (1978). Language as social semiotic : the social interpretation of language and meaning. London, England: Arnold.

Halliday, M. A. K. (1994). An introduction to functional grammar (2nd ed.). London: E. Arnold.

Hegarty, M., Carpenter, P. A., \& Just, M. A. (1991). Diagrams in the comprehension of scientific texts Handbook of reading research, Vol. 2. (pp. 641-668). Hillsdale, NJ, US: Lawrence Erlbaum Associates, Inc.

Kress, G., Jewitt, C., Ogborn, J., \& Tsatsarelis, C. (2001). Multimodal teaching and learning: the rhetorics of the science classroom: London: Continuum.

Kress, G., \& van Leeuwen, T. (2006). Reading images : the grammar of visual design (2nd edition ed.). London; New York: Routledge.

Lemke, J. L. (1990). Talking science: language, learning and values: Norwood, NJ: Ablex.

Lemke, J. L. (1998). Multiplying meaning: visual and verbal semiotics in scientific text. In J. Martin \& R. Veel (Eds.), Reading Science (pp. 87-113). London; New York: Routledge.

Lincoln, Y. S., \& Guba, E. G. (1985). Naturalistic Inquiry. Newbury Park, CA: Sage.

Meneses, A., Escobar, J.-P., \& Véliz, S. (2018). The effects of multimodal texts on science reading comprehension in Chilean fifth-graders: text scaffolding and comprehension skills. International Journal of Science Education, 40(18), 2226-2244.

Namdar, B., \& Shen, J. (2016). Intersection of argumentation and the use of multiple representations in the context of socioscientific issues. International Journal of Science Education, 38(7), 1100-1132. doi:10.1080/09500693.2016.1183265

New London Group. (1996). A pedagogy of multiliteracies: Designing social futures. Harvard Educational Review, 66, 60-92.

O'Halloran, K. L. (2000). Classroom discourse in mathematics: A multisemiotic analysis. Linguistics and Education, 10(3), 359-388.

Oliveira, D. K. B. S., Justi, R., \& Mendonça, P. C. C. (2015). The Use of Representations and Argumentative and Explanatory Situations. International Journal of Science Education, 37(9), 1402-1435. doi:10.1080/09500693.2015.1039095

O'Toole, M. (1994). The language of displayed art. Rutherford: Fairleigh Dickinson University Press.

O'Toole, M. (2006). Opera Ludentes: the Sydney Opera House at work and play. In K. L. O'Halloran (Ed.), Multimodal discourse analysis : systemic-functional perspectives (pp. vi, 252 p.). London ; New York: Continuum.

Oxford Cambridge and RSA. (2015). A Level Biology Drawing Skills Retrieved from http://www.ocr.org.uk/Images/251799-drawing-skills-booklet-handbook.pdf. 
To cite this article: Kok-Sing Tang, Mihye Won \& David Treagust (2019): Analytical framework for student-generated drawings, International Journal of Science Education, DOI: 10.1080/09500693.2019.1672906

Prain, V., Tytler, R., \& Peterson, S. (2009). Multiple Representation in Learning About Evaporation. International Journal of Science Education, 31(6), 787-808. doi:10.1080/09500690701824249

Prain, V., \& Tytler, R. (2012). Learning Through Constructing Representations in Science: A framework of representational construction affordances. International Journal of Science Education, 34(17), 2751-2773. doi:10.1080/09500693.2011.626462

Quillin, K., \& Thomas, S. (2015). Drawing-to-Learn: A Framework for Using Drawings to Promote Model-Based Reasoning in Biology. CBE Life Sciences Education, 14(1), es2. doi:10.1187/cbe.14-08-0128

Tang, K.-S. (2011). Reassembling curricula concepts: A multimodal communicative approach to the study of curriculum and instruction. International Journal of Science and Mathematics Education, 9, 109-135. doi:10.1007/s10763-010-9222-7

Tang, K.-S. (2013). Instantiation of multimodal semiotic systems in science classroom discourse. Language Sciences, 37, 22-35. doi:10.1016/j.langsci.2012.08.003

Tang, K.-S. (2016). The interplay of representations and patterns of classroom discourse in science teaching sequences. International Journal of Science Education, 38(13), 2069-2095. doi:10.1080/09500693.2016.1218568

Tang, K.-S. (2019). Metalanguage for describing \& analyzing multimodal discourse of science. In K. Danielsson (Chair), Research traditions on languages \& literacies in science education. SIG symposium conducted at the European science education research association (ESERA) biannual conference, Bologna, Italy.

Tang, K.-S., Delgado, C., \& Moje, E. B. (2014). An integrative framework for the analysis of multiple and multimodal representations for meaning-making in science education. Science Education, 98(2), 305-326.

Tang, K.-S., Ho, C., \& Putra, G. B. (2016). Developing multimodal communication competencies: A case of disciplinary literacy focus in Singapore. In Using multimodal representations to support learning in the science classroom (pp. 135-158). New York: Springer.

Treagust, D. F., Won, M., \& McLure, F. (2017). Multiple representations and students' conceptual change in science. In T. Amin \& O. Levrini (Eds.), Converging perspectives on conceptual change: Mapping an emerging paradigm in the learning sciences (pp. 121-128). London: Routledge

Wilson, R. E., \& Bradbury, L. U. (2016). The pedagogical potential of drawing and writing in a primary science multimodal unit. International Journal of Science Education, 38(17), 2621-2641. doi:10.1080/09500693.2016.1255369

White, R., \& Gunstone, R. F. (1992). Probing understanding. London ; New York: Falmer. Vygotsky, L. (1986). Thought and language (Translation newly rev. and edited / by Alex Kozulin ed.). Cambridge, Mass.: MIT Press. 